\title{
Is vaping better than smoking for cardiorespiratory and muscle function?
}

\author{
Mohammad Z. Darabseh, ${ }^{1}$ James Selfe, ${ }^{2}$ Christopher I. Morse, ${ }^{3}$ Hans Degens 4,5 \\ ${ }^{I}$ School of Healthcare Science to Department of Life Sciences, Manchester Metropolitan University, Manchester, UK \\ ${ }^{2}$ Department of Health Professions, Manchester Metropolitan University, Manchester, UK \\ ${ }^{3}$ Department of Sport and Exercise Sciences, Manchester Metropolitan University, Manchester, UK \\ ${ }^{4}$ Department of Life Sciences, Manchester Metropolitan University, Manchester, UK \\ ${ }^{5}$ Institute of Sport Science and Innovations, Lithuanian Sports University, Kaunas, Lithuania
}

\begin{abstract}
Cigarette smoking is a risk factor for respiratory disorders, cardiovascular diseases and even decrements in muscle function. Electronic cigarette use (vaping) is considered a healthier alternative to cigarette smoking and may help in smoking cessation. However, the effects of vaping are not clear yet and particularly the long-term effects of vaping are largely unknown. Some reports suggest that vaping maybe as harmful for $e . g$. respiratory function, as cigarette smoking. In this narrative review the effects of vaping and cigarette smoking on respiratory, cardiovascular and muscle function are compared. Overall, vaping has been found to cause similar effects as smoking on lung function and cardiovascular function. Future studies are needed to clarify the severity of smoking- and vaping-induced decrements on muscle function.
\end{abstract}

Key words: Vaping; electronic cigarette; cardiorespiratory; lung function; smoking; muscle function.

Correspondence: Mohammad Z. Darabseh, Manchester Metropolitan University, School of Healthcare Science to Department of Life Sciences, John Dalton Building, Chester Street, Manchester M1 5GD, UK.

Tel.: +44.7707647570 .

E-mail: darabseh.moh@gmail.com

Contributions: All authors have participated in drafting the article, revising it critically for important intellectual content, in conception and design and final approval of the version to be published and agreed to be accountable for all aspects of the work.

Conflict of interest: All authors declare no conflict of interest.

Funding: None.

Availability of data and materials: The data used to support the findings of this study are available from the corresponding author upon request.

Ethics approval and consent to participate: Not applicable.

Consent for publication: Not applicable. 


\section{Introduction}

Cigarette packages contain warning labels like 'Smoking kills' and 'Smoking clogs the arteries and causes heart attacks and stroke'. These labels illustrate the tragic truth that smoking is a major risk factor for the development of cancer, cardiovascular diseases and respiratory disorders. It causes more than 7 million deaths per year globally [1] and in 2016, 77,900 deaths in the United Kingdom (UK) were directly or indirectly attributable to smoking [2]. Yet, these labels do not appear enough of a deterrent as about 7.2 million of the UK population are smokers [3]. These disastrous effects of smoking develop unperceivably slowly and only later in life the detrimental health issues become evident [4], a phenomenon referred to as 'the smoking time-bomb'. To make matters worse, 'The beneficial cognitive effects of nicotine have implications for initiation of smoking and maintenance of tobacco dependence' [5].

Any means to administer nicotine, but without the concomitant inhalation of the more than 4,000 toxic substances in cigarette smoke, such as acrolein, carbon monoxide, acetaldehyde and cyanide, would thus be preferable to cigarette smoking. E-cigarettes containing nicotine are considered to do this. The success of ecigarettes in reducing smoking is reflected by the fact that about $54.1 \%$ of the current 3.6 million adult e-cigarette users in the UK are ex-smokers [6].

There is, however, concern that e-cigarettes may singularly stimulate uptake of smoking, particularly in youth, and have an acute effect on cardiorespiratory health, even in the absence of smoking $[7,8]$. Additionally, there are potential risks with vaping during pregnancy and lactation on the development of the child in the womb and health of the newborn baby [9-11]. Indeed, vapours from ecigarettes contain, besides nicotine and the respiratory irritant propylene glycol, toxic substances also seen in cigarette smoke, such as acrolein, acetaldehyde, formaldehyde, and reactive oxygen species. As seen in animal studies, these toxic substances may well cause oxidative stress and negative effects on cardiovascular and respiratory function after vaping [7], casting doubt on the idea that e-cigarettes are a suitable 'healthy' alternative to normal cigarettes. Yet, there are only basic regulations for the composition of e-cigarette liquids (as described in https:/www.gov.uk/guidance/e-cigarettes-regulations-for-consumer-products).

The potential health risk of e-cigarettes led the Forum of International Respiratory Societies to release a position statement that concluded: 'As a precaution, electronic nicotinic delivery devices should be restricted or banned until more information about their safety is available' [8]. There is, thus an unmet need to know the effects of vaping on cardio-respiratory function in humans, and how this is related to the daily vaping volume and/or for how long one has been vaping. Therefore, the aim of this narrative review is to compare the effects of vaping and cigarette smoking on cardiovascular, respiratory and muscle function.

\section{Vaping and smoking cessation}

Since 1963 cigarette companies have been working to invent a new smoking system such as electronic nicotine delivery systems (ENDS) that heats, instead of burns, tobacco to reduce harm, and presents as a socially acceptable alternative to smoking $[12,13]$. The credit of inventing the e-cigarette as an alternative to smoking goes to Hon Lik, a Chinese pharmacist and inventor, whose heavysmoking father died from lung cancer [14,15]. Many companies worldwide have adopted this technology and started marketing ecigarettes as an harmless and safe alternative to cigarette smoking [16]. The focus of this review is therefore on e-cigarettes rather than heated tobacco products (HTPs) like e.g. iQOS.

Most smokers are aware of the harmful effects of cigarette smoking. Since the introduction of e-cigarettes in 2003, many smokers have turned to electronic cigarettes as they are thought to be less harmful, instead of nicotine replacement therapy (NRT) to help them quit smoking [17-22]. In 2019, 7.1\% of the adult population of Great Britain used e-cigarettes [6] and in the European Union (EU), the use of e-cigarettes increased from $7.2 \%$ in 2012 to $11.6 \%$ in 2014 [23]. The potential of e-cigarettes or vaping to facilitate smoking cessation is illustrated by the $80 \%$ decrease in the use of normal cigarettes after 6 months of vaping [24], and other studies showing an up to $50 \%$ decrease in smoked cigarettes 24 months after taking up vaping $[25,26]$. In addition, smoking cessation was reported to be as high as $8.7 \% 52$ weeks after taking up vaping [26]. In the UK, a recent trial for smoking cessation showed that using e-cigarette accompanied by behavioural support, such as face-to-face support, was more effective than NRT [27]. This is a strong evidence that vaping indeed can reduce smoking.

Nicotine replacement therapies expose users to low doses of nicotine [ 7 to $14 \mathrm{mg} / 24$-hour patch or 2 to $4 \mathrm{mg}$ per piece of gum) and have been approved as medicinal products by the United States (US) Food and Drug Administration (FDA) [28]. E-cigarettes are not approved by the FDA and can be bought over the counter or online also in Europe [28]. The liquid in e-cigarettes have widely different nicotine concentrations, varying from 8 to 24 $\mathrm{mg} / \mathrm{ml}$ per cartridge, but even doses up to $100 \mathrm{mg} / \mathrm{ml}$ are readily available [28] and pose a real risk of nicotine poisoning [29]. There is, indeed, not enough evidence that vaping is safe and has no, or minor, negative health effects. On the contrary, a study using online forums reported 326 negative health-related effects of vaping, including effects on the respiratory, circulatory, sensory, digestive and neurological systems [30].

\section{The dangers of nicotine in e-cigarettes}

An e-cigarette is composed of a rechargeable lithium battery, vaporizing chamber and a cartridge that contains the vaping liquid that consists, among other substances, of nicotine, glycerol, propylene glycol, glycerine, and tobacco flavouring [31,32], although some vaping liquids may be free of nicotine. Nicotine is easily absorbed by the mucus membrane, skin, gastrointestinal tract and respiratory airways [33] and acts as a neurotransmitter that in turn stimulates the release of dopamine, which contributes to the feeling of pleasure and satisfaction as part of the reward pathway [34]. It is this effect of nicotine that makes smoking so addictive [35]. As mentioned above, the dose of nicotine in e-cigarettes can be very high; typically, a 5$\mathrm{mL}$ bottle of e-cigarette refill solution consists of $20 \mathrm{mg} / \mathrm{ml}$ nicotine (that is $100 \mathrm{mg} /$ bottle) [36]. The life threatening dose of nicotine is around 30 to $40 \mathrm{mg}$ in adults and $10 \mathrm{mg}$ in children [36]. This high dose combined with unlimited vaping poses a potential health risk as it has been shown that acute contact to high concentrations of inhaled nicotine, or even skin contact e.g. after spills of nicotine-containing solutions, may cause nausea, vomiting or dizziness [33,37]. Such risks are even higher in vaping than in smoking, where such poisonous nicotine levels rarely occur [38]. In fact, many successful and unsuccessful suicide attempts through intravenous and oral intake of the nicotine solution intended for e-cigarette cartridges have been reported [39-41].

\section{Chemical components of e-cigarettes}

Besides nicotine there are other chemicals in the vaping liquids, where propylene glycol constitutes $90 \%$ of the e-cigarette liq- 
uid [42]. While propylene glycol is often used to produce the smoke in special events like rock concerts and is considered harmless, prolonged and repeated exposure to propylene glycol vapour has been reported to cause cough, irritations of the eyes and lungs [43], and to increase the risk of acquiring asthma [44]. Vaping liquid also contains $1 \%$ diethylene glycol, a known carcinogen [31, 45], when non-pharmaceutical grade propylene glycol is used [46]. While many of the flavours in e-liquids are safe when ingested and widely used in the food industry, the potential dangers of inhaling flavours are not yet fully investigated, but there are indications they may have a negative effect on lung health. For example, diacetyl is used in butter and safe when ingested, but when heated and inhaled it might cause bronchiolitis [47]. In addition, some studies have shown that e-cigarettes release aromatic, particularly the carcinogenic component, polycyclic hydrocarbons, that have a pathogenic effect on human lung cells [48], and contain esters, aldehydes, acids or saccharides that are cariogenic [49]. In addition to these compounds, there are many more carcinogenic compounds in e-cigarette liquids $[45,50]$, particularly trace metals (i.e., cadmium, arsenic, chromium, nickel, and lead), and tobacco-specific Nnitrosamines, and all these substances can in some cases reach concentrations even higher than in cigarette smoke [51]. Perhaps most surprising, given that smoking is a primary risk factor for pulmonary diseases, is that the most common used e-cigarette refill liquids are classified as respiratory irritants, allergens, inducers of asthmatic symptoms or potentially causing breathing difficulties if inhaled [52].

There is as yet no strong evidence that passive exposure to vaping has adverse effects on health. However, the detrimental effects of passive smoking and the observation that nicotine released into the environment does not only affect those who inhale it, but may also affect non-smokers and non-vapers via nicotine left on surfaces e.g. furniture, carpets and clothes [53], strongly hints to the dangers of passive exposure to the e-cigarette aerosols.

\section{Effects of vaping and smoking on respiratory function}

Cigarette smoke irritates the lining of the bronchial tubes causing them to swell and produce mucus to remove smoke particles [54]. Emphysema may develop when smoke particles irritate the alveolar walls and inflammation stimulates the release of proteases, enzymes that lead to the destruction of elastic fibres and collagen, which subsequently culminate in the destruction of the alveolar walls [54, 55]. Over time, this can lead to a decreased elastic recoil of the lung, chronic bronchitis and narrowing of the bronchial tubes that increases the resistance, and hence, cost of breathing $[54,56]$. Ultimately, this progressive decrease in lung function can develop into COPD [57] that is diagnosed in $6.6 \%$ of the US population, of which $75 \%$ are smokers [58].

In contrast to smoking, the effects of vaping on human health and respiratory function are poorly investigated [59], but it has been shown that vaping for just 5 min increased peripheral airway resistance [60]. This is, however, not unequivocal, as another study found no acute effects of active vaping on lung function [61]. Whatever the cause of the discrepancy, it has been suggested that the increased peripheral airway resistance after $5 \mathrm{~min}$ of vaping [60] is partially caused by nicotine [59]. Indeed, nicotine inhalation $(0-64 \mathrm{mg} / \mathrm{ml})$ showed a dose-dependent increase in the amount of coughing and airway obstruction in non-smokers, which may be a consequence of the stimulation of afferent nerve endings in the bronchial mucosa by nicotine, which in turn triggers parasympathetic cholinergic pathways leading to bronchoconstriction [62]. Nicotine is, however, not the whole explanation, as respiratory symptoms, and airway inflammation were even found in vapers who used nicotine-free e-cigarettes [63].

Over time, the above effects of vaping may cause acute smallairway constriction and airway epithelial injury [64] that may be linked to increased risk of wheezing and respiratory symptoms similar to those seen in cigarette smokers [65]. McCauley et al. [66] presented a case study of a 42-year old woman diagnosed with exogenous lipoid pneumonia due to vaping. She had a history of $7-$ months productive cough, fevers and dyspnoea which occurred at the same time of her use of e-cigarettes. After several laboratory tests, glycerine, which is a component added to e-cigarette liquid to produce visible smoke to simulate the cigarette smoking experience, was found to be the causative agent. The symptoms improved by vaping cessation [66]. The above example may be considered anecdotal, but in a study of 30 vapers who never smoked, it was seen that the forced expiratory volume in one second $\left(\mathrm{FEV}_{1}\right)$ and forced expiratory volume in one second/forced vital capacity $\left(\mathrm{FEV}_{1} / \mathrm{FVC}\right)$ were significantly lower than those in controls (nonvapers and non-smokers) [67], similar to that seen in smokers [68, 69] (Figure 1).
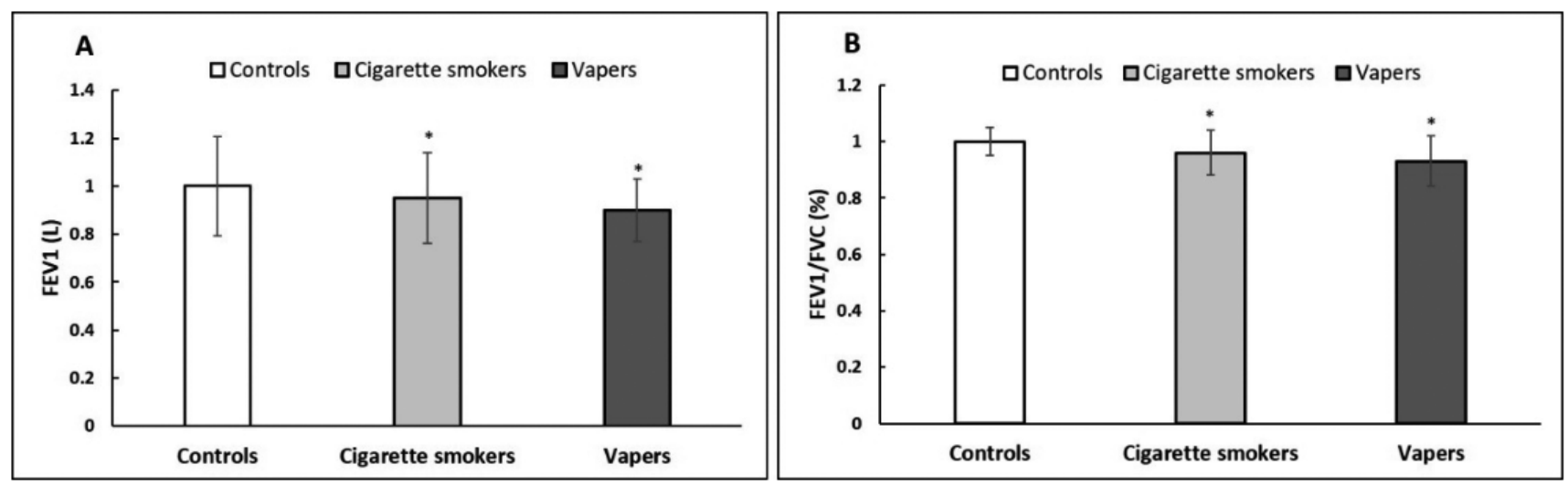

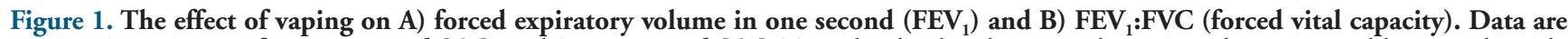
mean \pm SD. Data are from Meo et al. [67], and Sparrow et al. [69]. To make the data between the two studies comparable, in each study the data were normalised to the control group. ${ }^{*}$ Different from controls at $\mathbf{p}<0.05$. 
In contrast to the above cross-sectional study where vapers and non-vapers were compared [67], in a 3.5-year prospective study no significant decrements in spirometry or diffusion capacity were found in vapers [70]. Perhaps studies with a larger sample size are needed, as there are studies that have also not seen any significant effect of smoking on respiratory function [71]. Overall, combined with the detrimental impact of vaping on the lungs of mice [72] the data suggest that vaping has a detrimental effect on lung function.

\section{Effects of vaping and cigarette smoking on cardio- vascular function}

Smokers suffer from a reduced exercise capacity that is not only attributable to a reduction in aerobic capacity, but also in increased metabolic cost of breathing [73-75]. Smoking increases blood pressure (BP), heart rate (HR), the risk factor for atherosclerosis $[76,77]$ and has been shown to impair cardiovascular function, increase vascular resistance, and decrease vasodilation and hence tissue blood flow [76]. The impaired vasodilation [78] can even occur after short-term smoking [79]. Such an effect is not limited to the peripheral vasculature. Indeed, a narrowing of the coronary arteries, and hence decrease in coronary blood flow and increase coronary resistance, despite an increase in myocardial oxygen demand, has been reported as a result of acute cigarette smoking [80]. The authors suggested that such ongoing effects with prolonged smoking may well contribute to the adverse cardiovascular consequences of cigarette smoking, such as myocardial infarction and cardiac failure [80].

There are not many studies on the effects of vaping on exercise tolerance or cardiovascular function, but Polosa et al. [70] reported no significant changes in BP and HR in regular e-cigarette users. However, results of Polosa et al. [70] should be considered with caution, because of the small sample size (9 vapers vs 12 cigarette smokers). A meta-analysis that included 11 studies with a total of 283 participants concluded that vaping does acutely increase resting HR and diastolic $\mathrm{BP}$ [81], similar to the effects of cigarette smoking, but perhaps less pronounced [82]. These effects combined with the associated increased myocardial demand for oxygen and nutrients and vasoconstriction may lead to myocardial ischemia $[83,84]$. Part, or perhaps even most, of these effects may be caused by nicotine [85], where nicotine increases the HR and BP primarily by sympathetic neural stimulation and systemic release of catecholamines [84]. Nicotine-free vaping does not impair vasodilation, increase BP or HR [85], increase arterial stiffness [86, 87], or cause palpations at rest [63]. The absence of a cardiovascular stimulus from nicotine-free vaping is significant, as people using other forms of nicotine delivery (smokers, NRT, dual use vapers and smokers) all had similar levels of circulating nicotine compared to nicotine-free vapers [88], though others report higher levels in smokers than vapers [82]. However, nicotine cannot be the sole culprit as vaping non-nicotinic aerosols also caused impaired femoral artery flow-mediated dilation [89]. Based on the culmination of acute responses, this suggests that a chronic e-cigarette user has an increased risk of increased arterial stiffness and associated adverse cardiovascular outcomes and comparative studies are required to assess whether the effects of smoking on cardiovascular health are more severe than those of vaping. Based on the acute impact of vaping on resting cardiorespiratory and vascular function, we expect that vaping will impair endurance exercise capacity. At this point however, more research is required to determine whether the impact of vaping on endurance exercise capacity, both in the short and long term, is significant and less than that from smoking.

\section{Effects of vaping and cigarette smoking on muscle function and muscle size}

Many studies have described the negative effects of smoking on skeletal muscle function and morphology, specifically, the thigh muscles [90]. One aspect is decreased muscle fatigue resistance [71] associated with reduced muscle oxidative capacity [91] and a slow twitch to fast twitch fibre type transition [92]. A diminished oxygen delivery due to the interaction of carbon monoxide (CO) with haemoglobin may hamper the mitochondria to resynthesize Adenosine triphosphate (ATP). The ability of the mitochondria to synthesise ATP can be further aggravated by mitochondrial dysfunction due to interaction of $\mathrm{CO}$ and other substances in cigarette smoke with elements of oxidative phosphorylation, and combined with the other changes already discussed, cause a reduction in muscle contractile endurance [93]. Furthermore, smoking could promote skeletal muscle wasting via smoking-induced inflammation that increases protein breakdown and decreases protein synthesis $[93,94]$ and results in a reduced maximal force-generating capacity of the muscles from smokers $[95,96]$.

There are as yet no studies on the effects of vaping on muscle function and/or skeletal muscle size.

\section{Conclusions}

In conclusion, despite vaping being marketed as safer and healthier smoking alternative and a smoking cessation technique, vaping has been found to cause similar effects as smoking on lung function and cardiovascular function. There are, however, no studies on the effects of vaping on muscle function and size. To assess whether these effects are less than those seen during smoking, future studies should seek to systematically compare the differences in severity in the smoking- and vaping-induced decrements in humans.

\section{References}

1. World Health Organization. WHO report on the global tobacco epidemic, 2017: monitoring tobacco use and prevention policies. Geneva: World Health Organization; 2017.

2. Office for National Statistics. Adult smoking habits in the UK. London: Dandy Booksellers Ltd.; 2017.

3. Office for National Statistics. Adult smoking habits in the UK: 2018. Available from: https://www.ons.gov.uk/releases/adultsmokinghabitsintheuk2018

4. Lopez AD, Collishaw NE, Piha T. A descriptive model of the cigarette epidemic in developed countries. Tob Control 1994;3:242-7. 
5. Heishman SJ, Kleykamp BA, Singleton EG. Meta-analysis of the acute effects of nicotine and smoking on human performance. Psychopharmacology (Berl) 2010;210:453-69.

6. Action on Smoking and Health. Use of e-cigarettes (vapourisers) among adults in Great Britain. 2019. Available from: https://ash.org.uk/information-and-resources/fact-sheets/statistical/use-of-e-cigarettes-among-adults-in-great-britain-2019/

7. Korfei M. The underestimated danger of E-cigarettes - also in the absence of nicotine. Respir Res 2018;19:159.

8. Schraufnagel DE, Blasi F, Drummond MB, Lam DC, Latif E, Rosen MJ, et al. Electronic cigarettes. A position statement of the forum of International Respiratory Societies. Am J Respir Crit Care Med 2014;190:611-8.

9. Kuehn B. Vaping and pregnancy. JAMA 2019;321:1344.

10. McAlinden KD, Chan YL, Kota A, Chen H, Oliver BG, Sharma P. Maternal E-cigarette vaping enhances development of allergic asthma in the offspring. In: Proceedings Int Conf American Thoracic Society, 2017; Abstract A7333.

11. Orzabal MR, Lunde-Young ER, Ramirez JI, Howe SY, Naik VD, Lee J, et al. Chronic exposure to e-cig aerosols during early development causes vascular dysfunction and offspring growth deficits. Translat Res 2019;207:70-82.

12. Glantz SA, Forbes ER. The cigarette papers. Berkeley: University of California Press; 1996.

13. Ling PM, Glantz SA. Tobacco industry consumer research on socially acceptable cigarettes. Tob Control 2005; 14:e3.

14. Lik H. Electronic atomization cigarette. US Patent US8393331B2; 2004.

15. Demick B. A high-tech approach to getting a nicotine fix. Los Angeles Times [Internet]; 2009. Available from: https://www.latimes.com/archives/la-xpm-2009-apr-25-fgchina-cigarettes 25 -story.html

16. Dutra LM, Grana R, Glantz SA. Philip Morris research on precursors to the modern e-cigarette since 1990. Tob Control 2017;26:e97-105.

17. Foulds J, Veldheer S. Commentary on Etter \& Bullen (2011): Could E-cigs become the ultimate nicotine maintenance device? Addiction 2011;106:2029.

18. Etter J-F. Electronic cigarettes: a survey of users. BMC Public Health 2010;10:231.

19. Etter JF, Bullen C. Electronic cigarette: users profile, utilization, satisfaction and perceived efficacy. Addiction 2011;106:2017-28.

20. Dawkins L, Turner J, Roberts A, Soar K. 'Vaping'profiles and preferences: an online survey of electronic cigarette users. Addiction 2013;108:1115-25.

21. Dockrell M, Morrison R, Bauld L, McNeill A. E-cigarettes: prevalence and attitudes in Great Britain. Nicotine Tob Res 2013; 15:1737-44.

22. Farsalinos KE, Romagna G, Tsiapras D, Kyrzopoulos S, Voudris V. Evaluating nicotine levels selection and patterns of electronic cigarette use in a group of "vapers" who had achieved complete substitution of smoking. Subst Abuse 2013;7:139-46.

23. Filippidis FT, Laverty AA, Gerovasili V, Vardavas CI. Twoyear trends and predictors of e-cigarette use in 27 European Union member states. Tob Control 2017;26:98-104.

24. Polosa R, Caponnetto P, Morjaria JB, Papale G, Campagna D, Russo C. Effect of an electronic nicotine delivery device (eCigarette) on smoking reduction and cessation: a prospective 6-month pilot study. BMC Public Health 2011;11:786.

25. Polosa R, Morjaria JB, Caponnetto P, Campagna D, Russo C, Alamo A, et al. Effectiveness and tolerability of electronic cigarette in real-life: a 24-month prospective observational study. Intern Emerg Med 2014;9:537-46.

26. Caponnetto P, Campagna D, Cibella F, Morjaria JB, Caruso M,
Russo C, et al. EffiCiency and Safety of an eLectronic cigAreTte (ECLAT) as tobacco cigarettes substitute: a prospective 12-month randomized control design study. PloS One 2013;8:e66317.

27. Hajek P, Phillips-Waller A, Przulj D, Pesola F, Myers Smith K, Bisal N, et al. A randomized trial of e-cigarettes versus nicotine-replacement therapy. N Engl J Med 2019;380:629-37.

28. Kempton SJ, Burish NM, Rao VK. Electronic cigarettes: have you asked your patients about vaping? Plast Reconstr Surg 2014; 133:907e.

29. European Commission. Proposal for a Directive of the European Parliament and of the Council on the approximation of the laws, regulations and administrative provisions of the Member States concerning the manufacture, presentation and sale of tobacco and related products. Brussels: European Commission; 2012.

30. Hua M, Alfi M, Talbot P. Health-related effects reported by electronic cigarette users in online forums. J Med Internet Res 2013; 15:e59.

31. Westenberger BJ. Evaluation of e-cigarettes. St Louis: Department of Health and Human Services, Food and Drug Administration, Center for Drug Evaluation and Research, Division of Pharmaceutical Analysis; 2009.

32. Cobb NK, Abrams D. E-cigarette or drug-delivery device. N Engl J Med. 2011;365(3):193-5.

33. Callahan-Lyon P. Electronic cigarettes: human health effects. Tob Control 2014;23:ii36-ii40.

34. Bressan RA, Crippa JA. The role of dopamine in reward and pleasure behaviour-review of data from preclinical research. Acta Psychiatr Scand 2005;111:14-21.

35. Benowitz NL. Nicotine addiction. N Engl J Med 2010;362: 2295-303.

36. Cameron JM, Howell DN, White JR, Andrenyak DM, Layton ME, Roll JM. Variable and potentially fatal amounts of nicotine in e-cigarette nicotine solutions. Tob Control 2014;23:77-8.

37. Ordonez J, Forrester MB, Kleinschmidt K. Electronic cigarette exposures reported to poison centers. Clin Toxicol 2013;51: 685.

38. Centers for Disease Control Prevention. Ingestion of cigarettes and cigarette butts by children--Rhode Island, January 1994July 1996. MMWR Morb Mortal Wkly Rep 1997;46:125-8.

39. Thornton S, Oller L, Sawyer T, editors. Fatal intravenous injection of electronic "eLiquid" solution. Clin Toxicol 2013;51: 683.177

40. Valento M. Nicotine poisoning following ingestion of eLiquid. Clin Toxicol 2013;51:683-4.

41. Christensen LB, van't Veen T, Bang J. Three cases of attempted suicide by ingestion of nicotine liquid used in e-cigarettes. Clin Toxicol 2013;51:290.85

42. Laugesen M. Second safety report on the Ruyan ${ }^{\circledR}$ e-cigarette. Cell 2008;27:4375.

43. Wieslander G, Norbäck D, Lindgren T. Exp.erimental exposure to propylene glycol mist in aviation emergency training: acute ocular and respiratory effects. Occup Environ Med 2001;58:649-55.

44. Choi H, Schmidbauer N, Sundell J, Hasselgren M, Spengler J, Bornehag CG. Common household chemicals and the allergy risks in pre-school age children. PloS One 2010;5:e13423.

45. Goniewicz ML, Knysak J, Gawron M, Kosmider L, Sobczak A, Kurek J, et al. Levels of selected carcinogens and toxicants in vapour from electronic cigarettes. Tob Control 2014;23:1339.

46. Cahn Z, Siegel M. Electronic cigarettes as a harm reduction strategy for tobacco control: a step forward or a repeat of past mistakes? J Public Health Policy 2011;32:16-31.

47. Harber P, Saechao K, Boomus C. Diacetyl-induced lung disea- 
se. Toxicol Rev 2006;25:261-72.

48. Rankin GD, Wingfors H, Uski O, Hedman L, Ekstrand-Hammarström B, Bosson J, et al. The toxic potential of a fourth-generation E-cigarette on human lung cell lines and tissue explants. J Appl Toxicol 2019;39(8): 1143-54.

49. Kim SA, Smith S, Beauchamp C, Song Y, Chiang M, Giuseppetti A, et al. Cariogenic potential of sweet flavors in electronic-cigarette liquids. PLoS One 2018;13:e0203717.

50. Talhout R, Schulz T, Florek E, van Benthem J, Wester P, Opperhuizen A. Hazardous compounds in tobacco smoke. Int J Environ Res Public Health 2011;8:613-28.

51. Williams M, Villarreal A, Bozhilov K, Lin S, Talbot P. Metal and silicate particles including nanoparticles are present in electronic cigarette cartomizer fluid and aerosol. PLoS One 2013;8:e57987.

52. Vardavas C, Tzatzarakis M, Vardavas A, Girvalaki C, Stivaktakis P, Nikolouzakis T, et al. Evaluation of respiratory irritants among the most popular e-cigarette refill liquids across 9 European countries. Eur Respir J 2017;50:OA1978.

53. Matt GE, Quintana PJ, Hoh E, Zakarian JM, Dodder NG, Record RA, et al. Persistent tobacco smoke residue in multiunit housing: Legacy of permissive indoor smoking policies and challenges in the implementation of smoking bans. Prev Med Rep 2020:101088.

54. Hogg JC, Chu F, Utokaparch S, Woods R, Elliott WM, Buzatu $\mathrm{L}$, et al. The nature of small-airway obstruction in chronic obstructive pulmonary disease. N Engl J Med 2004;350:264553.

55. Centers for Disease Control Prevention. How tobacco smoke causes disease: The biology and behavioral basis for smokingattributable disease: A report of the surgeon general. Atlanta: Centers for Disease Control and Prevention; 2010.

56. Stănescu D, Sanna A, Veriter C, Kostianev S, Calcagni P, Fabbri L, et al. Airways obstruction, chronic expectoration, and rapid decline of FEV1 in smokers are associated with increased levels of sputum neutrophils. Thorax 1996;51:26771.

57. Wüst RC, Degens H. Factors contributing to muscle wasting and dysfunction in COPD patients. Int $\mathrm{J}$ Chron Obstruct Pulmon Dis 2007;2:289.

58. Salvi SS, Barnes PJ. Chronic obstructive pulmonary disease in non-smokers. Lancet 2009;374:733-43.

59. Palazzolo DL. Electronic cigarettes and vaping: a new challenge in clinical medicine and public health. A literature review. Front Public Health 2013;1:56.

60. Vardavas CI, Anagnostopoulos N, Kougias M, Evangelopoulou V, Connolly GN, Behrakis PK. Short-term pulmonary effects of using an electronic cigarette: impact on respiratory flow resistance, impedance, and exhaled nitric oxide. Chest 2012;141:1400-6.

61. Flouris AD, Chorti MS, Poulianiti KP, Jamurtas AZ, Kostikas $\mathrm{K}$, Tzatzarakis $\mathrm{MN}$, et al. Acute impact of active and passive electronic cigarette smoking on serum cotinine and lung function. Inhal Toxicol 2013;25:91-101.

62. Hansson L, Choudry NB, Karlsson JA, Fuller RW. Inhaled nicotine in humans: effect on the respiratory and cardiovascular systems. J Appl Physiol (1985) 1994;76:2420-7.

63. Vakali S, Tsikrika S, Gennimata SA, Kaltsakas G, Palamidaw A, Koulouris N, et al. E-cigarette acute effect on symptoms and airways inflammation: Comparison of a nicotine containing with a non-nicotine device. Eur Respir J 2013;42:P1055.

64. Chaumont M, Bernard A, Pochet S, Melot C, El Khattabi C, Reye F, et al. High-wattage e-cigarettes induce tissue hypoxia and lower airway injury: A randomized clinical trial. Am J Respir Crit Care Med 2018;198:123-6.

65. Li D, Sundar IK, McIntosh S, Ossip DJ, Goniewicz ML,
O'Connor RJ, et al. Association of smoking and electronic cigarette use with wheezing and related respiratory symptoms in adults: cross-sectional results from the Population Assessment of Tobacco and Health (PATH) study, wave 2. Tob Control 2020;29:140-7.

66. McCauley L, Markin C, Hosmer D. An unexpected consequence of electronic cigarette use. Chest 2012;141:1110-3.

67. Meo SA, Ansary MA, Barayan FR, Almusallam AS, Almehaid AM, Alarifi NS, et al. Electronic cigarettes: impact on lung function and fractional exhaled nitric oxide among healthy adults. Am J Mens Health 2019;13:1557988318806073.

68. Kiter G, Ucan E, Ceylan E, Kilinc O. Water-pipe smoking and pulmonary functions. Respir Med 2000;94:891-4.

69. Sparrow D, Stefos T, Bossé R, Weiss ST. The relationship of tar content to decline in pulmonary function in cigarette smokers. Am Rev Respir Dis 1983;127:56-8.

70. Polosa R, Cibella F, Caponnetto P, Maglia M, Prosperini U, Russo C, et al. Health impact of e-cigarettes: a prospective 3.5year study of regular daily users who have never smoked. Sci Rep 2017;7:13825.

71. Wüst RC, Morse CI, De Haan A, Rittweger J, Jones DA, Degens H. Skeletal muscle properties and fatigue resistance in relation to smoking history. Eur J Appl Physiol 2008;104:103.

72. Glynos C, Bibli SI, Katsaounou P, Pavlidou A, Magkou C, Karavana V, et al. Comparison of the effects of e-cigarette vapor with cigarette smoke on lung function and inflammation in mice. Am J Physiol Lung Cell Mol Physiol 2018;315:L66272.

73. Lauria V, Sperandio E, de Sousa T, de Oliveira Vieira W, Romiti M, de Toledo Gagliardi A, et al. Evaluation of doseresponse relationship between smoking load and cardiopulmonary fitness in adult smokers: A cross-sectional study. Rev Port Pneumol (2006). 2017;23(2):79-84.

74. de Borba AT, Jost RT, Gass R, Nedel FB, Cardoso DM, Pohl $\mathrm{HH}$, et al. The influence of active and passive smoking on the cardiorespiratory fitness of adults. Multidiscip Respir Med 2014;9:34.

75. Misigoj-Durakovic M, Bok D, Soric M, Dizdar D, Durakovic Z, Jukic I. The effect of cigarette smoking history on muscular and cardiorespiratory endurance. J Addict Dis 2012;31:389-96.

76. Campisi R, Czernin J, Schöder H, Sayre JW, Marengo FD, Phelps ME, et al. Effects of long-term smoking on myocardial blood flow, coronary vasomotion, and vasodilator capacity. Circulation 1998;98:119-25.

77. Groppelli A, Giorgi D, Omboni S, Parati G, Mancia G. Persistent blood pressure increase induced by heavy smoking. J Hypertens 1992;10:495-9.

78. Celermajer DS, Sorensen KE, Gooch V, Spiegelhalter D, Miller O, Sullivan I, et al. Non-invasive detection of endothelial dysfunction in children and adults at risk of atherosclerosis. Lancet 1992;340:1111-5.

79. Lekakis J, Papamichael C, Vemmos C, Nanas J, Kontoyannis D, Stamatelopoulos S, et al. Effect of acute cigarette smoking on endothelium-dependent brachial artery dilatation in healthy individuals. Am J Cardiol 1997;79:529-31.

80. Quillen JE, Rossen JD, Oskarsson HJ, Minor RL, Lopez JAG, Winniford MD. Acute effect of cigarette smoking on the coronary circulation: constriction of epicardial and resistance vessels. J Am Coll Cardiol 1993;22:642-7.

81. Skotsimara G, Antonopoulos A, Oikonomou E, Ioakeimidis N, Tsalamandris S, Georgakopoulos C, et al. Exposure to e-cigarette adversely affects blood pressure and heart rate in healthy individuals: A Systematic review and meta-analysis. Circulation 2018;138:A11507-A.

82. Yan XS, D'Ruiz C. Effects of using electronic cigarettes on nicotine delivery and cardiovascular function in comparison 
with regular cigarettes. Regul Toxicol Pharmacol 2015;71:2434.

83. Battista L, Di Iorio M, Tancredi M, Acconcia MC, Torromeo C, Barilla F, et al. Cardiovascular effects of electronic cigarettes [abstract]. American Heart Association; 2013.

84. Benowitz NL, Fraiman JB. Cardiovascular effects of electronic cigarettes. Nat Rev Cardiol. 2017;14:447-56.

85. Chaumont M, de Becker B, Zaher W, Culié A, Deprez G, Mélot $\mathrm{C}$, et al. Differential effects of e-cigarette on microvascular endothelial function, arterial stiffness and oxidative stress: A randomized crossover trial. Sci Rep 2018;8:10378.

86. Lundbäck M, Antoniewicz L, Brynedal A, Bosson J. Acute effects of active e-cigarette inhalation on arterial stiffness. Eur Respir J 2017;50:OA1979.

87. Antoniewicz L, Brynedal A, Hedman L, Lundbäck M, Bosson JA. Acute Effects of electronic cigarette inhalation on the vasculature and the conducting airways. Cardiovasc Toxicol 2019:1-10.

88. Shahab L, Goniewicz ML, Blount BC, Brown J, McNeill A, Alwis KU, et al. Nicotine, carcinogen, and toxin exposure in long-term e-cigarette and nicotine replacement therapy users: A cross-sectional study. Ann Intern Med 2017;166:390-400.

89. Caporale A, Langham MC, Guo W, Johncola A, Chatterjee S, Wehrli FW. Acute effects of electronic cigarette aerosol inhalation on vascular function detected at quantitative MRI. Radiology 2019;293:97-106.
90. Larsson L, Örlander J. Skeletal muscle morphology, metabolism and function in smokers and non-smokers. A study on smoking-discordant monozygous twins. Acta Physiol Scand 1984;120:343-52.

91. Degens H, Veerkamp J. Changes in oxidative capacity and fatigue resistance in skeletal muscle. Int J Biochem 1994;26:8718.

92. Örlander J, Kiessling KH, Larsson L. Skeletal muscle metabolism, morphology and function in sedentary smokers and nonsmokers. Acta Physiol Scand 1979;107:39-46.

93. Degens H, Gayan-Ramirez G, van Hees HW. Smoking-induced skeletal muscle dysfunction. From evidence to mechanisms. Am J Respir Crit Care Med 2015;191(620-5.

94. Petersen AMW, Magkos F, Atherton P, Selby A, Smith K, Rennie MJ, et al. Smoking impairs muscle protein synthesis and increases the expression of myostatin and MAFbx in muscle. Am J Physiol Endocrinol Metab 2007;293:E843-8.

95. Barreiro E, Peinado VI, Galdiz JB, Ferrer E, Marin-Corral J, Sanchez F, et al. Cigarette smoke-induced oxidative stress: a role in chronic obstructive pulmonary disease skeletal muscle dysfunction. Am J Respir Crit Care Med 2010;182:477-88.

96. Seymour J, Spruit M, Hopkinson N, Natanek S, Man WC, Jackson A, et al. The prevalence of quadriceps weakness in COPD and the relationship with disease severity. Eur Respir J 2010;36:81-8 